\title{
Evaluation of Dog Food Authenticity through Lipid Profile Using GC-FID and ESI-MS
}

\author{
Roberta da Silveira, ${ }^{\circledR a}$ Patrícia D. S. dos Santos, ${ }^{b}$ Jessica S. Pizzo, ${ }^{\odot b}$ Nayane Mattos, ${ }^{b}$ \\ Matheus C. de Castro, ${ }^{b}$ Oscar O. Santos ${ }^{\circledR * b}$ and Jesuí V. Visentainer ${ }^{\circledR a}$ \\ ${ }^{a}$ Departamento de Ciência de Alimentos, Universidade Estadual de Maringá (UEM), 87020-900 Maringá-PR, Brazil \\ ${ }^{b}$ Departamento de Química, Universidade Estadual de Maringá (UEM), 87020-900 Maringá-PR, Brazil
}

\begin{abstract}
Considering the increasing number of low cost vegetable oil product adulterations, it is necessary to assess the authenticity of the lipid sources used in the dog food manufacture, consequently different brands and classifications of feed were analyzed to verify the product authenticity by gas chromatography (GC) with flame ionization detector (FID) and by electrospray ionization mass spectrometry (ESI-MS). Fatty acid (FA) composition analysis was performed to compare the FAs amount in samples with the respective guarantee levels stated by the manufacturers on its product label. Gas chromatography with flame ionization detector (GC-FID) results for omega-3 and 6 percentages are within the limits presented by each manufacturer, while the timnodonic + cervonic acids amount information presented on feed sample labels is not in accordance with GC-FID results. Consequently, the samples were analyzed by ESI-MS, the results exposed the chicken oil presence in the feed and eicosapentaenoic (EPA) + docosahexaenoic (DHA) acids absence, since no lipid profiles similar to fish oils or triacylglycerols (TAGs) containing these two FAs were found. Thus, the information presented on labels are in disagreement with the results obtained both by GC-FID FA composition analysis and by ESI-MS lipid profile analysis. Principal component analysis (PCA) confirmed that the main contribution was from FAs found by GC-FID.
\end{abstract}

Keywords: dog food, fatty acid composition, product quality, GC-FID, ESI-MS, lipid profile

\section{Introduction}

The pet food industry is continuously developing and seeking new ingredients for greater animal welfare and health. The feed must be balanced in order to meet all the animal nutritional requirements, ${ }^{1}$ as well as it should contain sources of protein, fiber, carbohydrates, fats and minerals. ${ }^{2,3}$ Dog food is classified according to the ingredients quality and its cost, being divided in standard, premium and super-premium. The standard has low-quality and low-cost ingredients; premium has intermediary ingredients and cost; and super-premium are formulated with high-quality and high-cost ingredients. ${ }^{4}$ Generally, in feed composition are present flours of meat, bone and chicken viscera, in addition to phosphates, cereal flours and bran, and food additives such as acidulants, antioxidants and flavorings. ${ }^{5}$ The lipid sources used in feed are usually chicken fat, bovine tallow, swine lard, fish oil and vegetable oils. ${ }^{6}$

Aiming the animal health, the nutritional supplementation with omega-3 (n-3) and omega-6 (n-6) is widely used.

*e-mail: oliveirasantos.oscardeoliveira@gmail.com
Studies $^{7}$ suggest that the incorporation of essential fatty acids, such as linoleic (18:2n-6) and $\alpha$-linolenic acids (18:3n-3), is related to lower rate of behavioral changes, as well as to increase learning capacity and visual acuity in pups. In addition, the use of n- 3 and n- 6 enriched dog food is also considered a secure option to assist in the treatment of canine atopic dermatitis. ${ }^{8}$

Eicosapentaenoic (20:5n-3, EPA) and docosahexaenoic (22:6n-3, DHA) fatty acids (FAs) are part of the n-3 FAs family, which is important in animal health. EPA is involved in the eicosanoids synthesis, particularly prostaglandins, leukotrienes, and thromboxanes, competing with arachidonic acid (20:4n-6, AA) for cyclooxygenase and 5-lipoxygenase enzymes, leading to increased production of anti-inflammatory eicosanoids, rather than pro-inflammatory eicosanoids derived from AA. ${ }^{9}$ DHA is essential for the neurological system development and it is present in the retinal membrane. Furthermore, EPA and DHA have beneficial effects on the immune and inflammatory systems, assist in the protection of cardiac and renal functions (anti-inflammatory and antihypertensive actions) and stimulate learning ability. ${ }^{10-12}$ 
Observing the crescent adulterated products number with the addition of low cost vegetable oils, it is crucial to evaluate the authenticity of the lipid source used in the manufacture of dog food. Therefore, diverse feed brands and classifications were analyzed in order to verify fraud existence regarding the FAs composition, mainly EPA and DHA. Consequently, fatty acid composition and lipid profile of each feed were obtained by gas chromatographic (GC) techniques with flame ionization detector (FID) and mass spectrometry with electrospray ionization (ESI-MS), respectively.

\section{Experimental}

A fatty acid methyl esters standard mixture (FAMEs 189-19) and methyl tricosanoate (23:0me) were purchased from Millipore Sigma (St. Louis, MO, USA). The other reagents: chloroform, methanol, $n$-heptane, sulfuric and hydrochloric acids, were also purchased from Millipore Sigma (Darmstadt, Germany) and used without further purification. ${ }^{13}$

Dog feed considered n-3 and n-6 sources (composition on the label) from different classifications and brands available in the Brazilian market were purchased at pet shops in the city of Maringá, Paraná, Brazil (2325'31"S, $\left.51^{\circ} 56^{\prime} 15^{\prime \prime} \mathrm{W}\right)$. Table 1 shows the classification and minimum levels of n-3, n-6 and EPA + DHA presented on the label.

\section{Fatty acid composition by GC-FID}

Figueiredo et al. ${ }^{14}$ direct methylation method was employed in order to extract and prepare the FAMEs. $100.0 \mathrm{mg}$ of sample was weighed in a $10 \mathrm{~cm}$ test tube, then $2.0 \mathrm{~mL}$ of sodium hydroxide $\left(1.5 \mathrm{~mol} \mathrm{~L}^{-1}\right.$ in methanol) was added. The sample was macerated with a glass rod in order to form a thin film and increase the contact surface. Then, the test tubes were placed in ultrasound bath for $8 \mathrm{~min}$. After the alkaline reaction was over, $2.0 \mathrm{~mL}$ of sulfuric acid or hydrochloric acid (1.5 mol L $\mathrm{L}^{-1}$ in methanol) was added, and the test tube was again placed in the ultrasound bath for $8 \mathrm{~min}$. Then, $1.0 \mathrm{~mL}$ of $n$-heptane was added, the tubes were shaken for $30 \mathrm{~s}$ and then centrifuged at $2000 \mathrm{rpm}$ for $1.00 \mathrm{~min}$. After that, $500 \mu \mathrm{L}$ of internal standard (23:0me) was added, and the upper phase was collected and injected into the GC. The procedure was performed in an ultrasonic bath model Eco-Sonics Q 5.9/25 (Unique, São Paulo, Brazil) with $165 \mathrm{~W}$ of power and $25 \mathrm{kHz}$. FAMEs were separated on a Thermo GC, Trace Ultra 3300 model, equipped with FID, with automatic injector and fused silica capillary column CP-7420 (Select FAME, $100 \mathrm{~m}$ long, $0.25 \mathrm{~mm}$ internal diameter and $0.25 \mu \mathrm{m}$ cyanopropyl). Gas flow as follows: $1.2 \mathrm{~mL} \mathrm{~min}^{-1}$ of $\mathrm{H}_{2}, 30 \mathrm{~mL} \mathrm{~min}^{-1}$ of $\mathrm{N}_{2}$, 35 and $300 \mathrm{~mL} \mathrm{~min}^{-1}$ of $\mathrm{H}_{2}$ and synthetic air, respectively, to the detector flame. The injected volume was $1.0 \mu \mathrm{L}$, using a sample split of 40:1, with injector and detector temperatures being 250 and $230{ }^{\circ} \mathrm{C}$, respectively. Heating ramp was applied in the column, initiating the temperature at $165{ }^{\circ} \mathrm{C}$ for $18 \mathrm{~min}$ and raised to $235^{\circ} \mathrm{C}$ with heating rate of $4{ }^{\circ} \mathrm{C} \mathrm{min}{ }^{-1}$, remaining for $20 \mathrm{~min} .{ }^{13}$ FAMEs were identified by comparing its retention times with standards (FAME Mix, C4-C24, Sigma-Aldrich (St. Louis, MO, USA)) and the results were expressed as $\mathrm{mg} \mathrm{g}^{-1}$ of total lipids, determined automatically by integration of peak areas through Chromquest ${ }^{\mathrm{TM}} 5.0$ software.

\section{Lipid profile by direct infusion with ESI(+)-MS}

The feed lipid fraction was extracted according to the methodology described by Figueiredo et al. ${ }^{14}$ Then, $50 \mu \mathrm{L}$ of the extracted oil was diluted in chloroform $(950 \mu \mathrm{L}){ }^{15}$

Table 1. Classification and levels of omega-6, omega-3 and EPA + DHA presented on the label

\begin{tabular}{|c|c|c|c|c|}
\hline Sample & Classification & Omega-6 / $\left(\mathrm{g} \mathrm{kg}^{-1}\right)$ & Omega-3 / $\left(\mathrm{mg} \mathrm{kg}^{-1}\right)$ & $\mathrm{EPA}+\mathrm{DHA} /\left(\mathrm{mg} \mathrm{kg}^{-1}\right)$ \\
\hline 1 & premium & $20(2 \%)$ & $1500(0.15 \%)$ & $600(0.06 \%)$ \\
\hline 2 & premium & $20(2 \%)$ & $3000(0.3 \%)$ & $420(0.042 \%)$ \\
\hline 3 & premium & $20(2 \%)$ & $3000(0.3 \%)$ & ND \\
\hline 4 & premium & $20(2 \%)$ & $3000(0.3 \%)$ & $420(0.042 \%)$ \\
\hline 5 & premium & $25(2.5 \%)$ & $2500(0.25 \%)$ & ND \\
\hline 6 & premium & $24(2 \%)$ & $3000(0.3 \%)$ & ND \\
\hline 7 & super premium & $20(2 \%)$ & $3000(0.3 \%)$ & $700(0.07 \%)$ \\
\hline 8 & standard & $12(1.2 \%)$ & $2400(0.24 \%)$ & ND \\
\hline 9 & super premium & $15(2 \%)$ & ND & $3100(0.31 \%)$ \\
\hline 10 & standard & $10(1.0 \%)$ & $1800(0.18 \%)$ & ND \\
\hline
\end{tabular}

EPA: eicosapentaenoic acid; DHA: docosahexaenoic acid; ND: not available. 
$1.0 \mathrm{~mL}$ of methanol/chloroform $(9: 1, \mathrm{v} / \mathrm{v})$ was added in $5.0 \mu \mathrm{L}$ of this solution and then $20 \mu \mathrm{L}$ of ammonium formate $\left(0.10 \mathrm{~mol} \mathrm{~L}^{-1}\right.$ in methanol) were added..$^{16}$

The final solution was infused directly into a triplequadrupole Xevo-TQD mass spectrometer equipped with electrospray $\mathrm{Z}$ spray ${ }^{\mathrm{TM}}$ ionization source (Waters, Milford, MA, USA). The lipid profiles were obtained in the ratio range of $\mathrm{m} / \mathrm{z} 100$ to 1200 and extracted in positive mode $(\mathrm{ESI}(+))$. ESI $(+)$ source parameters were as follows: source temperature of $150^{\circ} \mathrm{C}$, desolvation temperature of $200^{\circ} \mathrm{C}$, capillary voltage of $3.0 \mathrm{kV}$ and cone voltage of $20.0 \mathrm{~V}$. High purity nitrogen was produced by nitrogen generator (NM32LA, Peak Scientific ${ }^{\circledR}$, Renfrewshire, Scotland) and it was used as desolvation gas with flow rate of $500 \mathrm{~L} \mathrm{~h}^{-1}$. The sample solutions were injected with a continuous flow of $10.0 \mu \mathrm{L} \mathrm{min}^{-1}$. Data were processed using MassLynx ${ }^{\mathrm{TM}}$ software.

\section{Statistical analysis}

The results obtained from the FA composition analysis by GC-FID were submitted to analysis of variance (ANOVA), the means were compared using the Tukey test, with significance level of $95 \%$, and the results obtained by ESI(+)-MS were analyzed by principal component analysis (PCA), through the RStudio software. ${ }^{17}$

\section{Results and Discussion}

\section{Fatty acid composition by GC-FID}

Feed manufacturers must present the guarantee levels on its products labels. ${ }^{1}$ These levels establish the product nutritional quality offered to the consumer, demonstrating that the quality standard is dependent on the adequate quality control during and after the production process, plus the raw material used. Among the information presented in the guarantee levels are: FAs levels such as n-3, n-6, EPA and DHA.

FA composition analysis was carried out with the objective of comparing the FAs amount of the samples with the respective guarantee levels declared by the manufacturers. The results are presented in Table 2.

As shown in Table 2, oleic acid (18:1n-9) was the major FA in all samples analyzed, followed by linoleic (18:2n-6) and palmitic acid (16:0). Myristic acid (14:0) was found in the range of 0.61 to $1.23 \%, 16: 0$ acid in the range of 21.78 to $24.87 \%$, stearic acid (18:0) was found in the range of 5.83 to $9.85 \%, 18: 1 \mathrm{n}-9$ acid was found in the range of 31.98 to $39.48 \%, 18: 2 \mathrm{n}-6$ acid was found in the range of 23.62 to $28.96 \%$ and $\alpha$-linolenic acid (18:3n-3) had a concentration of 1.10 to $2.65 \%$. Furthermore, it was not possible to identify EPA and DHA FAs in any of the samples analyzed.

Among the polyunsaturated (PUFA) found, 18:2n-6 and 18:3n-3 are essential FAs not synthesized by the body, being considered extremely important in animal feed, once it is required to consume it exclusively through diet. Plus, these FAs are precursors of $n-3$ and $n-6$ and its ingestion is essential to combat health problems, such as inflammations, behavioral changes, and it acts in cancer prevention. ${ }^{18}$

In all samples analyzed, there is the addition of chicken oil. This information is presented in the labels of each sample and was confirmed with FA composition analysis

Table 2. Fatty acid composition of pet food samples (1-10) obtained by GC-FID

\begin{tabular}{|c|c|c|c|c|c|c|c|c|c|c|}
\hline \multirow{2}{*}{$\begin{array}{l}\text { Fatty } \\
\text { acid }\end{array}$} & \multicolumn{10}{|c|}{ Pet food sample / \% } \\
\hline & 1 & 2 & 3 & 4 & 5 & 6 & 7 & 8 & 9 & 10 \\
\hline 4:0 & $0.77 \pm 0.010^{\mathrm{bc}}$ & $0.93 \pm 0.02^{\text {bed }}$ & $0.79 \pm 0.20^{\mathrm{ab}}$ & $0.83 \pm 0.10^{\mathrm{de}}$ & $0.82 \pm 0.05^{\mathrm{a}}$ & $0.61 \pm 0.010^{\mathrm{ab}}$ & $0.78 \pm 0.050^{\mathrm{bc}}$ & $0.91 \pm 0.15^{\mathrm{e}}$ & $0.76 \pm 0.020^{\text {ce }}$ & $1.23 \pm 0.030^{\mathrm{bcd}}$ \\
\hline $16: 0$ & $22.40 \pm 0.70^{\mathrm{bc}}$ & $22.88 \pm 0.54^{\mathrm{bc}}$ & $21.93 \pm 0.55^{\mathrm{ab}}$ & $24.81 \pm 0.90^{\mathrm{f}}$ & $21.90 \pm 0.70^{\mathrm{a}}$ & $22.60 \pm 0.65^{\mathrm{c}}$ & $24.41 \pm 0.50^{\mathrm{d}}$ & $24.87 \pm 0.45^{\mathrm{d}}$ & $21.78 \pm 0.20^{\mathrm{e}}$ & $22.41 \pm 0.55^{\mathrm{a}}$ \\
\hline $16: 1 n-7$ & $3.12 \pm 0.10^{\mathrm{abc}}$ & $2.99 \pm 0.10^{\mathrm{abc}}$ & $2.81 \pm 0.10^{\mathrm{ab}}$ & $3.70 \pm 0.55^{\mathrm{e}}$ & $3.18 \pm 0.10^{\mathrm{ab}}$ & $4.25 \pm 0.07^{\mathrm{bd}}$ & $3.89 \pm 0.10^{\mathrm{cd}}$ & $3.92 \pm 0.60^{\mathrm{ad}}$ & $3.29 \pm 0.10^{\text {de }}$ & $2.21 \pm 0.050^{\mathrm{a}}$ \\
\hline 18:0 & $7.39 \pm 0.32^{\mathrm{b}}$ & $8.30 \pm 0.17^{\text {bd }}$ & $7.43 \pm 0.20^{\mathrm{ab}}$ & $5.83 \pm 0.50^{\mathrm{d}}$ & $6.840 \pm 0.20^{\mathrm{a}}$ & $6.88 \pm 0.20^{\mathrm{bc}}$ & $6.99 \pm 0.10^{\mathrm{bc}}$ & $8.14 \pm 0.10^{\mathrm{cd}}$ & $7.71 \pm 0.40^{\mathrm{c}}$ & $9.85 \pm 0.20^{b}$ \\
\hline $18: 1 n-9$ & $35.11 \pm 0.82^{\circ}$ & $34.63 \pm 0.65^{\circ}$ & $35.40 \pm 0.75^{\mathrm{bc}}$ & $38.80 \pm 0.54^{\mathrm{f}}$ & $39.48 \pm 0.80^{\mathrm{b}}$ & $35.78 \pm 0.90^{\mathrm{d}}$ & $36.51 \pm 0.65^{\mathrm{d}}$ & $35.50 \pm 0.70^{d}$ & $33.78 \pm 0.75^{\mathrm{e}}$ & $31.98 \pm 0.30^{\mathrm{a}}$ \\
\hline $18: 1 \mathrm{n}-7$ & $1.38 \pm 0.030^{\mathrm{bd}}$ & $1.39 \pm 0.003^{\mathrm{bc}}$ & $1.37 \pm 0.05^{\mathrm{ab}}$ & $1.31 \pm 0.15^{\mathrm{e}}$ & $1.71 \pm 0.10^{\mathrm{bc}}$ & $1.78 \pm 0.010^{\mathrm{d}}$ & $1.44 \pm 0.020^{\mathrm{cd}}$ & $1.26 \pm 0.050^{\mathrm{bc}}$ & $1.79 \pm 0.10^{\mathrm{f}}$ & $1.28 \pm 0.050^{\mathrm{a}}$ \\
\hline $18: 2 n-6$ & $28.31 \pm 0.82^{\circ}$ & $27.28 \pm 0.56^{\mathrm{bc}}$ & $28.31 \pm 0.65^{b}$ & $23.62 \pm 0.75^{d}$ & $24.33 \pm 0.90^{\mathrm{a}}$ & $25.45 \pm 0.75^{\mathrm{bc}}$ & $24.65 \pm 0.65^{\mathrm{bc}}$ & $24.23 \pm 0.50^{\text {bc }}$ & $28.89 \pm 0.85^{\mathrm{e}}$ & $28.96 \pm 0.55^{\mathrm{a}}$ \\
\hline $18: 3 n-3$ & $1.55 \pm 0.030^{\mathrm{ab}}$ & $1.58 \pm 0.070^{\mathrm{a}}$ & $1.96 \pm 0.050^{\mathrm{a}}$ & $1.10 \pm 0.20^{\mathrm{b}}$ & $1.71 \pm 0.15^{\mathrm{a}}$ & $2.65 \pm 0.05^{\mathrm{c}}$ & $1.33 \pm 0.060^{\mathrm{ab}}$ & $1.17 \pm 0.15^{\mathrm{a}}$ & $2.00 \pm 0.05^{c}$ & $2.08 \pm 0.10^{\mathrm{a}}$ \\
\hline AGS & $30.53 \pm 1.05^{\mathrm{d}}$ & $32.11 \pm 0.73^{\mathrm{e}}$ & $30.15 \pm 0.90^{c}$ & $31.47 \pm 1.45^{\mathrm{h}}$ & $29.59 \pm 0.95^{\mathrm{a}}$ & $30.09 \pm 0.85^{\mathrm{e}}$ & $32.18 \pm 0.65^{\mathrm{f}}$ & $33.92 \pm 0.65^{g}$ & $30.25 \pm 0.60^{\mathrm{i}}$ & $33.49 \pm 0.80^{\mathrm{b}}$ \\
\hline AGMI & $39.61 \pm 0.95^{\mathrm{e}}$ & $39.01 \pm 0.74^{\mathrm{d}}$ & $39.58 \pm 0.90^{c}$ & $43.81 \pm 1.30^{\mathrm{j}}$ & $44.37 \pm 0.95^{\mathrm{b}}$ & $41.48 \pm 0.95^{\mathrm{f}}$ & $41.84 \pm 0.80^{\mathrm{h}}$ & $40.68 \pm 1.35^{g}$ & $38.86 \pm 0.910^{\mathrm{i}}$ & $35.47 \pm 0.40^{\mathrm{a}}$ \\
\hline UFA & $29.86 \pm 0.85^{\mathrm{g}}$ & $28.86 \pm 0.65^{\mathrm{cd}}$ & $30.27 \pm 0.70^{c}$ & $24.72 \pm 0.90^{\mathrm{h}}$ & $26.04 \pm 1.05^{\mathrm{a}}$ & $28.43 \pm 0.80^{f}$ & $25.98 \pm 0.70^{\mathrm{c}}$ & $25.40 \pm 0.65^{\mathrm{de}}$ & $30.89 \pm 0.90^{\mathrm{i}}$ & $31.04 \pm 0.65^{\mathrm{b}}$ \\
\hline
\end{tabular}

Average of three repetitions with their coefficients of variation. Values accompanied by different letters in the same line indicate significant difference $(p<0.05)$ by Tukey test. 14:0: myristic acid; 16:0: palmitic acid; 16:1n-7: palmitoleic; 18:0: stearic acid; 18:1n-9: oleic acid; 18:1n-7: vaccenic acid; 18:2n-6: linoleic acid; 18:3n-3: $\alpha$-linolenic acid; AGS: saturated fatty acid; AGMI: monounsaturated fatty acid; PUFA: polyunsaturated fatty acid. 
by GC-FID comparing the feed samples and the chicken oil analyse ${ }^{19}$ becoming clear that all analyzed samples have the same FA composition, predominating the FAs 18:1n-9, 18:2n-6 and 16:0.

Besides the chicken oil, on the labels of samples 1, 2, 4, 7 and 9, there is the information that fish oil is added in its composition, these being the main sources of EPA and DHA. ${ }^{13-20}$ However, the information on the amount of EPA + DHA, presented on the feed sample labels (Table 1), does not agree with the analysis results (Table 2). However, the results obtained by GC-FID on the percentages of omega- 3 and omega- 6 are within the limits presented by each manufacturer.

The extrusion applied in the processing of dry feed utilizes high temperatures, humidity and pressure, and assists to sterilize the food, reducing anti-nutritional factors, and improving digestibility. Nevertheless, the conditions modify physically and chemically numerous nutrients and the final product quality ${ }^{21}$ causing, for example, lipid oxidation.

In the study carried out by Ribeiro, ${ }^{22}$ which verified the oxidative changes occurring in extruded foods for cats containing poultry fat as lipid source, it was observed the reduction of fatty acid during the extrusion process step of processed foods. ${ }^{23}$

Thus, in this study, through the FA composition analysis by GC-FID, it can be seen that there are two possible conclusions: $(i)$ the manufacturer did not add DHA and EPA FAs in the analyzed feed or, (ii) the extraction process decreased the amount of DHA and EPA FAs at values lower than the guarantee levels displayed on feed labels. However, these guarantee levels should demonstrate the minimum amount of ingredients, such as DHA and EPA, present in the final product offered to the consumer.

\section{Lipid profile by direct infusion with ESI(+)-MS}

Oils and fats have an unique lipid profile. ${ }^{24}$ In order to verify the lipid profile of the oils extracted from the samples, ESI(+)-MS direct infusion technique was employed, once this technique has been used to characterize oils and fats rapidly and with little sample preparation, as well as it allows the observation of a characteristic pattern of the samples. ${ }^{15,16,25,26}$

Figures S1 to S10 (Supplementary Information (SI) section) show the lipid profiles of all feed samples obtained by $\mathrm{ESI}(+)-\mathrm{MS}$, in the ratio $\mathrm{m} / \mathrm{z} 100-1200$.

According to the figures it can be observed that all samples presented characteristic lipid profiles and similarity among them, also the FAs present in the feeds are in the triacylglycerols (TAG) form, due to the most abundant region of ions, predominantly in $\mathrm{m} / \mathrm{z} 800$ to 1000 .
The lipid profiles in the TAG region of all feed samples were similar to the profile presented by Cajka et al. ${ }^{19}$ for chicken oil. Hence, to confirm this similarity, chicken oil extraction was carried out by Bligh and Dyer ${ }^{27}$ and ESI(+)-MS direct infusion analysis was performed. Figure S11 (SI section) shows the lipid profile of the chicken oil, in the ratio $\mathrm{m} / \mathrm{z}, 50-1200$.

Thus, it is possible to observe the similarity between the profiles of all the feed samples (Figures S1 to S10, SI section) with the chicken oil profile (Figure S11, SI section), proving the presence of it in all feed samples.

Table 3 presents possible assignment of TAGs identified from ESI(+)-MS profiles, and the ions peaks were described in relative percentages. The most intense ion peak of all pet food samples, $\mathrm{m} / \mathrm{z} 874$ (TAG 52:3), was assigned as $100 \%$.

TAG composed of palmitic (P), oleic $(\mathrm{O})$, stearic $(\mathrm{S})$, palmitoleic $(\mathrm{Po})$, vaccenic $(\mathrm{V})$, linoleic $(\mathrm{L})$, linolenic $(\mathrm{Ln})$ acids, dominates the TAG profile of pet food. The major TAG pet food are 52:3, followed by 52:2, 54:4, 54:5, 52:4, and 54:3. These results are according to Porcari et al. ${ }^{24}$ and Cajka et al. ${ }^{19}$ for chicken oil lipid profile.

One of the possible TAGs found for $m / z 874$ is PLO, consisting of the FAs 16:0/18:2n-6/18:1n-9. These FAs were also found in greater amounts in the analysis performed by GC-FID (Table 1).

The feed producers of samples 1, 2, 4, 7, and 9 reported the presence of EPA and DHA at the guarantee levels on its labels. These two FAs come predominantly from fish oil, such as sardines and salmon. ${ }^{13}$ Therefore, to verify and compare the lipid profile of the sardine and salmon oils with the lipid profiles presented by the feed, both oils were extracted by Bligh and $\mathrm{Dyer}^{27}$ and the direct infusion analysis by ESI(+)-MS was carried out. Figures S12 and S13 (SI section) expose the lipid profiles of both fish oils, respectively, in the ratio $\mathrm{m} / \mathrm{z}, 100-1200$.

Hence, it can be observed that none of the feed samples (Figures S1 to S10, SI section) presented lipid profiles similar to the profiles analyzed for sardine (Figure S12, SI section) and salmon (Figure S13, SI section). Moreover, the profiles obtained for fish oils were also compared in this work with the lipid profiles of fish oils present in omega-3 capsules analyzed by direct infusion using ESI(+)-MS with ionization $\left[\mathrm{TAG}+\mathrm{NH}_{4}\right]^{+}$, and it was observed that the capsules have profiles similar to those obtained for sardine oil. ${ }^{26}$

The results obtained by ESI(+)-MS confirm the data obtained by GC-FID, showing the presence of chicken oil in the feed and the absence of EPA and DHA, since no lipid profiles were found similar to fish oils or TAGs containing these two FAs. 
Table 3. $\left[\mathrm{TAG}+\mathrm{NH}_{4}\right]^{+}$ions and relative abundances determined by ESI(+)-MS for pet food samples

\begin{tabular}{|c|c|c|c|c|c|c|c|c|c|c|c|c|c|}
\hline \multirow{2}{*}{$\begin{array}{l}{[\mathrm{TAG}+} \\
\left.\mathrm{NH}_{4}\right]^{+} m / z\end{array}$} & \multirow{2}{*}{$\mathrm{TAG}^{\mathrm{a}}$} & \multirow{2}{*}{ Composition } & \multirow{2}{*}{$\mathrm{CN} / \mathrm{DB}^{\mathrm{b}}$} & \multicolumn{10}{|c|}{ Sample / \% } \\
\hline & & & & 1 & 2 & 3 & 4 & 5 & 6 & 7 & 8 & 9 & 10 \\
\hline 820 & MPoO-MPoV-MPL-PpoPo & $\mathrm{C}_{51} \mathrm{H}_{94} \mathrm{O}_{6}$ & $48: 2$ & 4.9 & 5.2 & 4.4 & 5.4 & 4.9 & 5.6 & 6.1 & 6.7 & 4.0 & 4.8 \\
\hline 822 & MPO-MPV-PPPo & $\mathrm{C}_{51} \mathrm{H}_{96} \mathrm{O}_{6}$ & $48: 1$ & 7.5 & 8.4 & 6.8 & 8.9 & 8.1 & 8.1 & 9.8 & 11.7 & 5.3 & 8.3 \\
\hline 824 & PPP & $\mathrm{C}_{51} \mathrm{H}_{98} \mathrm{O}_{6}$ & $48: 0$ & 6.9 & 8.8 & 6.6 & 7.6 & 8.9 & 8.3 & 10.7 & 10.3 & 4.3 & 9.4 \\
\hline 844 & PPoLn-MLL-MVLn-MOLn-PoPoL & $\mathrm{C}_{53} \mathrm{H}_{94} \mathrm{O}_{6}$ & $50: 4$ & 5.3 & 5.5 & 4.9 & 5.5 & 5.2 & 6.0 & 5.6 & 5.3 & 5.8 & 5.4 \\
\hline 846 & OML-PPLn-PPoL-PoPoO-MSL-PoPoV-MVL & $\mathrm{C}_{53} \mathrm{H}_{96} \mathrm{O}_{6}$ & $50: 3$ & 16.4 & 17.3 & 15.6 & 19.2 & 17.7 & 20.2 & 19.3 & 19.5 & 16.7 & 15.5 \\
\hline 848 & MVO-MVV-SPoPo-PLP-SLM-MOO-PPoV-PPoO & $\mathrm{C}_{53} \mathrm{H}_{98} \mathrm{O}_{6}$ & $50: 2$ & 40.0 & 41.0 & 39.8 & 46.2 & 44.6 & 45.3 & 47.3 & 47.9 & 37.3 & 36.4 \\
\hline 850 & OPP-PpoS & $\mathrm{C}_{53} \mathrm{H}_{100} \mathrm{O}_{6}$ & $50: 1$ & 36.7 & 38.3 & 36.3 & 42.9 & 41.9 & 41.1 & 45.7 & 47.6 & 29.2 & 33.6 \\
\hline 852 & PPS-MSS & $\mathrm{C}_{53} \mathrm{H}_{102} \mathrm{O}_{6}$ & $50: 0$ & 14.4 & 19.6 & 17.8 & 21.5 & 20.9 & 20.9 & 23.1 & 24.2 & 14.4 & 18.6 \\
\hline 866 & PoLnLn & $\mathrm{C}_{55} \mathrm{H}_{92} \mathrm{O}_{6}$ & $52: 7$ & 2.5 & 3.4 & 2.7 & 2.2 & 2.1 & 3.1 & 2.8 & 3.7 & 2.0 & 5.0 \\
\hline 868 & SLnLn-PoLLn & $\mathrm{C}_{55} \mathrm{H}_{94} \mathrm{O}_{6}$ & $52: 6$ & 2.8 & 3.9 & 3.0 & 2.6 & 3.0 & 4.9 & 3.5 & 3.0 & 3.9 & 4.7 \\
\hline 870 & LLPo-PoVLn-PoOLn & $\mathrm{C}_{55} \mathrm{H}_{96} \mathrm{O}_{6}$ & $52: 5$ & 3.2 & 15.8 & 14.6 & 13.0 & 13.1 & 15.9 & 13.1 & 13.2 & 17.5 & 18.4 \\
\hline 872 & LLP-PoOL-SLnPo-PLnV-VLPo-PLnO & $\mathrm{C}_{55} \mathrm{H}_{98} \mathrm{O}_{6}$ & $52: 4$ & 65.3 & 65.5 & 66.3 & 57.1 & 58.6 & 61.7 & 58.4 & 64.4 & 65.1 & 69.4 \\
\hline 874 & PLO-SLnP-OPoV-VPoV-OPoO-PLV-SLPo & $\mathrm{C}_{55} \mathrm{H}_{100} \mathrm{O}_{6}$ & $52: 3$ & 100 & 100 & 100 & 100 & 100 & 100 & 100 & 100 & 100 & 100 \\
\hline 876 & POO-POV-SPoV-PVV-SOPo-SLP & $\mathrm{C}_{55} \mathrm{H}_{102} \mathrm{O}_{6}$ & $52: 2$ & 79.7 & 82.3 & 82.1 & 85.8 & 88.2 & 85.2 & 91.5 & 94.8 & 88.3 & 80.6 \\
\hline 878 & SPoS-SOP & $\mathrm{C}_{55} \mathrm{H}_{104} \mathrm{O}_{6}$ & $52: 1$ & 43.9 & 45.6 & 46.1 & 47.2 & 49.7 & 48.0 & 51.3 & 52.3 & 48.5 & 46.3 \\
\hline 880 & SSP & $\mathrm{C}_{55} \mathrm{H}_{106} \mathrm{O}_{6}$ & $52: 0$ & 16.4 & 17.1 & 17.2 & 15.5 & 18.7 & 17.7 & 18.4 & 22.1 & 18.9 & 21.8 \\
\hline 886 & OLM & $\mathrm{C}_{56} \mathrm{H}_{100} \mathrm{O}_{6}$ & $53: 4$ & 2.7 & 3.9 & 3.5 & 3.3 & 2.5 & 6.0 & 4.5 & 3.9 & 5.4 & 4.9 \\
\hline 888 & OOM & $\mathrm{C}_{56} \mathrm{H}_{102} \mathrm{O}_{6}$ & $53: 3$ & 2.9 & 7.3 & 6.2 & 6.1 & 4.2 & 10.6 & 8.2 & 8.1 & 8.7 & 7.5 \\
\hline 894 & LLLn-OLnLn-VLnLn & $\mathrm{C}_{57} \mathrm{H}_{96} \mathrm{O}_{6}$ & $54: 7$ & 4.6 & 9.5 & 9.7 & 6.4 & 6.9 & 12.5 & 7.8 & 9.0 & 10.5 & 13.6 \\
\hline 896 & LLL-OLLn-LVLn-SLnLn & $\mathrm{C}_{57} \mathrm{H}_{98} \mathrm{O}_{6}$ & $54: 6$ & 42.8 & 42.7 & 41.6 & 28.7 & 31.7 & 34.5 & 34.3 & 41.1 & 36.9 & 42.3 \\
\hline 898 & OLL-SLnL-OLnO-VLL-VLnV-OLnV & $\mathrm{C}_{57} \mathrm{H}_{100} \mathrm{O}_{6}$ & $54: 5$ & 79.2 & 75.7 & 74.9 & 56.5 & 62.9 & 62.8 & 64.4 & 69.4 & 68.6 & 87.1 \\
\hline 900 & SLnO-SLnV-OLV-SLL-VLV-OLO & $\mathrm{C}_{57} \mathrm{H}_{102} \mathrm{O}_{6}$ & $54: 4$ & 84.2 & 82.6 & 83.2 & 71.2 & 75.3 & 74.1 & 76.6 & 76.3 & 74.2 & 89.7 \\
\hline 902 & OVO-VVV-OOO-SLV-OVV-SLO-SLnS & $\mathrm{C}_{57} \mathrm{H}_{104} \mathrm{O}_{6}$ & $54: 3$ & 60.7 & 59.7 & 61.6 & 56.1 & 60.9 & 58.5 & 62.3 & 61.2 & 54.1 & 61.8 \\
\hline 904 & OOS-SSL-SVV & $\mathrm{C}_{57} \mathrm{H}_{106} \mathrm{O}_{6}$ & $54: 2$ & 33.9 & 33.9 & 35.6 & 31.9 & 35.5 & 33.4 & 36.0 & 35.2 & 30.5 & 35.4 \\
\hline 906 & SVV-SOO-SVO-SLS & $\mathrm{C}_{57} \mathrm{H}_{108} \mathrm{O}_{6}$ & $54: 1$ & 15.1 & 15.8 & 16.6 & 13.9 & 16.1 & 16.5 & 17.3 & 18.4 & 14.1 & 19.0 \\
\hline 908 & SSS & $\mathrm{C}_{57} \mathrm{H}_{110} \mathrm{O}_{6}$ & 54:0 & 6.6 & 7.0 & 8.3 & 5.4 & 6.7 & 7.9 & 7.3 & 9.3 & 6.1 & 10.0 \\
\hline
\end{tabular}

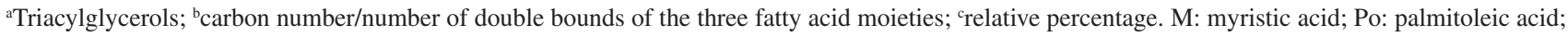
O: oleic acid; V: vaccenic acid; P: palmitic acid; L: linoleic acid; Ln: linolenic acid; S: stearic acid.

\section{Principal component analysis (PCA)}

PCA was performed to clarify the results contribution obtained by ESI(+)-MS. PC1 (65.1\%) and PC2 (21.2\%) explained $86.3 \%$ of the total variance, as proposed in Figure 1 .

A separation was observed in two distinct groups, in PC1 negative quadrant one group was formed by samples $1,2,3$ and 10 due to the closer signal strength $\mathrm{m} / z$, and the samples 1 and 2 contributed positively to PC2 and samples 3 and 10 contributed negatively to this separation.

In $\mathrm{PC} 1$ positive quadrant another group was formed by samples 5, 6, 7 and 8 due to the fact previously exposed. For this group only sample 6 contributed positively to PC2, while samples 5,7 and 8 contributed negatively to PC2.

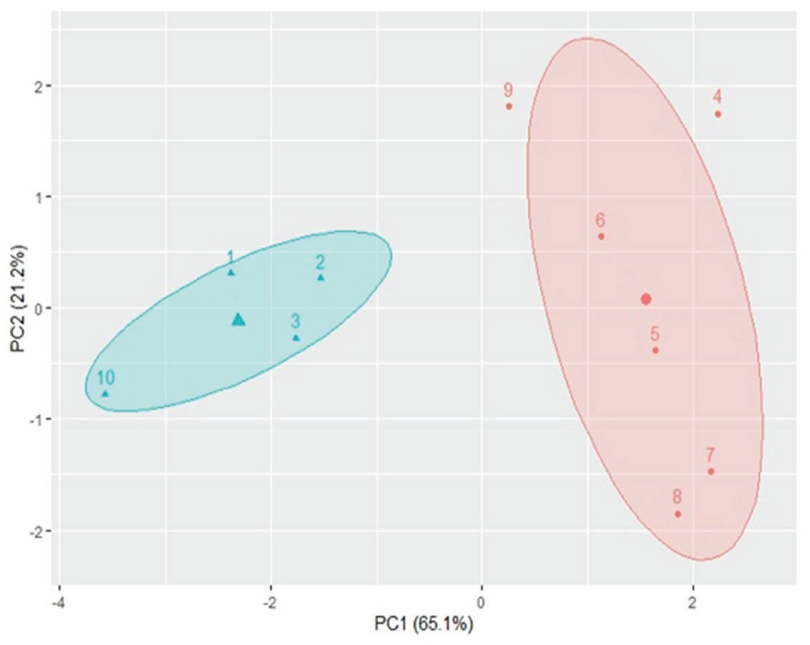

Figure 1. Score plots for $m / z$ of the samples PC1-PC2. 


\section{Conclusions}

The fatty acid composition obtained was compared to the dog food packaging labels samples, it was observed that the omega- 3 and omega- 6 amounts are within the limit determined by each manufacturer, however, the labeling information on the EPA and DHA concentrations are not in accordance with the results obtained by GC-FID nor by ESI-MS. PCA analysis revealed that PC1 and PC2 explained $86.3 \%$ of the total variance.

Consequently, the information displayed on the labels are in disagreement with the results obtained for the fatty acid composition analysis by GC-FID and for the lipid profile analysis by ESI(+)-MS.

\section{Supplementary Information}

Supplementary information is available free of charge at http://jbcs.sbq.org.br as PDF file.

\section{Acknowledgments}

The authors thank to CNPq, CAPES, Fundação Araucária for the financial support and grant of the scholarship. The Universidade Estadual de Maringá is also acknowledged for making the necessary technologies available for the development of this research.

\section{Author Contributions}

Roberta da Silveira was responsible for the visualization, writing original draft, review and editing; Patrícia D. S. dos Santos for the writing original draft, review and editing; Jéssica S. Pizzo for the methodology and validation; Nayane Mattos for the data curation and investigation; Matheus C. de Castro for the software and formal analysis; Oscar O. Santos for the supervision, project administration; Jesuí V. Visentainer for the resources and funding acquisition.

\section{References}

1. https://www.fda.gov/animal-veterinary/animal-health-literacy/ pet-food-labels-general, accessed in June 2020.

2. Thompson, A.; Top. Companion Anim. 2008, 23, 127.

3. Carciofi, A. C.; Teshima, E.; Bazolli, R. S.; Brunetto, M. A.; Vasconcellos, R. S.; Pereira, G. T.; Oliveira, L. D.; Rev. Bras. Saude Prod. Anim. 2009, 10, 489.

4. Flores, A. F. C.; Flores, D. C.; Oliveira, G.; Pizzuti, L.; da Silva, R. M. S.; Martins, M. A. P.; Bonacorso, H. G.; J. Braz. Chem. Soc. 2008, 19, 184.

5. Goes, R. H. T. B.; Silva, L. H. X.; Souza, K. A.; Alimentos e
Alimentação Animal; Editora UFGD: Dourados, MS, Brazil, 2013.

6. http://abinpet.org.br/wp-content/uploads/2020/05/manual_pet_ food_ed10_completo_digital.pdf, accessed in June 2020.

7. Heinemann, K. M. M.; Waldron, M. K.; Bigley, K. E.; Lees, G. E.; Bauer, J. E.; J. Nutr. 2005, 135, 1960.

8. Mueller, R. S.; Fieseler, K. V.; Fettman, M. J.; Zabel, S.; Rosychuk, R. A. W.; Ogilvie, G. K.; Greenwalt, T. L.; J. Small Anim. Pract. 2004, 45, 293.

9. National Research Council (NRC); Nutrient Requirements of Dogs and Cats; National Academies Press: Washington, DC, USA, 2006.

10. Olivry, T.; DeBoer, D. J.; Favrot, C.; Jackson, H. A.; Mueller, R. S.; Nuttall, T.; Pre'laud, P.; Vet. Dermatol. 2011, 21, 233.

11. Vaughn, D. M.; Reinhart, G. A.; Swain, S. F.; Lauten, D. S.; Garner, C. A.; Bourdeaux, M. K.; Spano, J. S.; Hoffman, C. E.; Conner, B.; Vet. Dermatol. 1994, 4, 163.

12. Bispo, P.; Batista, I.; Bernardino, R. J.; Bandarra, N. M.; Appl. Biochem. Biotechnol. 2014, 172, 1866.

13. Zeng, Y.; Araujo, P.; Grung, B.; Zhang, L.; Analyst 2011, 136, 1507.

14. Figueiredo I. L.; Claus T.; Santos Jr., O. O.; Almeida, V. C.; Magon, T. F. S.; Visentainer, J. V.; J. Chromatogr. A 2016, 1456, 235.

15. Silveira, R.; Vágula, J. M.; Figueiredo, I. L.; Claus, T.; Galuch, M. B.; Santos Jr., O. O.; Visentainer, J. V.; Food Res. Int. 2017, $102,43$.

16. Youzbachi, N.; Trabelsi, H.; Elfalleh, W.; Khaldi, A.; Nasri, N.; Tlili, N.; Arabian J. Chem. 2015, 12, 3302.

17. RStudio Team; RStudio: Integrated Development for $R$; RStudio, Boston, MA, USA, 2015.

18. Calviello, G.; Serini, S.; Piccioni, E.; Curr. Med. Chem. 2007, 14,3059 .

19. Cajka, T.; Danhelova, H.; Zachariasova, M.; Riddellova, K.; Hajslova, J.; Metabolomics 2013, 9, 545.

20. Kralovec, J. A.; Zhang, S.; Zhang, W.; Barrow, C. J.; Food Chem. 2012, 131, 639.

21. Kvamme, J. L.; Phillips, T. D.; Pet Food Technology; Watt Publishing Co.: Mt. Morris, Illinois, USA, 2003.

22. Ribeiro, P. M.: Oxidação Lípidica no Processo de Extrusão em Pet Food; MSc dissertation, Universidade Estadual de Maringá, Maringá, Brazil, 2018, available at http://www.pcs.uem.br/ppz/ trabalhos-de-conclusao/dissertacoes/2018/priscila-martinsribeiro, accessed in June 2020.

23. Rokey, G.; Plattner, B.; Pet Food Production; Wenger Mfg, Inc.: Sabetha, KS, USA, 1995.

24. Porcari, A. M.; Fernandes, G. D.; Barrera-Arellano, D.; Eberlin, M. N.; Alberici, R. M.; Analyst 2016, 141, 1172.

25. Pizzo, J. S.; Galuch, M. B.; Santos, P. D. S.; Santos, O. O.; Visentainer, L.; Eberlin, M. N.; Visentainer, J. V.; J. Braz. Chem. Soc. 2018, 29, 2457. 
26. Galuch, M. B.; Carbonera, F.; Magon, T. F. S.; da Silveira, R.; dos Santos, P. D. S.; Pizzo, J. S.; Santos, O. O.; Visentainer, J. V.; J. Braz. Chem. Soc. 2018, 29, 631.
27. Bligh, E. G.; Dyer, W. J.; Can. J. Biochem. Physiol. 1959, 37, 911.

Submitted: February 17, 2020

Published online: June 23, 2020 